\title{
Role of Cardiac Resynchronization Therapy in addition to optimum medical therapy in Decompensated Heart Failure.
}

\author{
Nilufar Fatema1 ${ }^{1}$ K.M.H.S. Sirajul Haque ${ }^{1}$, Md. Abu Siddique ${ }^{1}$, Sajal Banerjee ${ }^{1}$, A.T.M. Iqbal Hasan ${ }^{1}$ \\ Md. Khurshed Ahmed ${ }^{1}$, Md. Ashraf Uddin Sultan ${ }^{1}$, Neena Islam ${ }^{1}$, Jahanara Arju${ }^{1}$, Bikash Subedi ${ }^{1}$ \\ Mohammad Saifullah Patwary ${ }^{1}$ \\ 1 Department of Cardiology, Bangabandhu Sheikh Mujib Medical University (BSMMU), Shahbag, Dhaka, Bangladesh. \\ Address for Communication \\ Dr. Nilufar Fatema, Department of Cardiology, Bangabandhu Sheikh Mujib Medical University (BSMMU), Shahbagh, Dhaka. \\ E-mail: nilufar.fatema@gmail.com
}

\begin{abstract}
Decompensated heart failure is one of the major causes of morbidity and mortality in worldwide. Some of these patients suffer repeatedly after taking optimum medical therapy (OPT). Cardiac resynchronization therapy (CRT) has been shown to be an effective therapy for patients with heart failure and dyssynchrony.
\end{abstract}

\section{Introduction}

The risk of mortality is increased with an increase in QRS width or left bundle branch block (LBBB) in ECG in chronic heart failure. ${ }^{1}$ If the patient has LBBB, RV contraction occurs earlier than LV contraction. So it correlates with mechanical dyssynchrony, which is also known as the interventricular delay. Both the intraventricular and interventricular dyssynchrony lengthen systolic period and shorten diastolic period. In this way the proportion of the cardiac cycle during which there is diastolic filling of coronary arteries decreases. In addition there is a reduction of pump function in patients with and without coronary heart disease. These patients present with decompensated heart failure despite maximum medical treatment. In Europe, the readmission rates are due to an exacerbation or worsening of heart failure in approximately $50 \% .^{2}$ When left ventricular activation is delayed due to pathological changes in the intraventricular conduction system, benefit may be obtained from cardiac resynchronization therapy (CRT) because it is designed to eliminate the delay in activation of the LV free wall. Several large randomized trials have established the benefit of CRT in a selected group of patients with heart failure but a substantial amount that is about $30 \%$ of patients are non-responder.

So, patient selection is important before CRT implantation, as it is a costly device. Now many ongoing studies have started to identify the appropriate patients likely to respond to CRT device. A careful selection of patient may improve life expectancy in heart failure patients.

\section{Electrical and mechanical dyssynchrony of myocardial contraction}

Electrical dyssynchrony can be diagnosed by the duration of the QRS complex.
Interventricular dyssynchrony is described as early activation of right Ventricle and relatively late activation of inerventricular septum and then left ventricular lateral wall. It is a common phenomenon in heart failure patients with LBBB.

Intraventricular mechanical dyssynchrony is most commonly manifest by decreased septal motion and subsequent contraction of lateral wall. Intraventricular dyssynchrony appears to be more predictive of response to CRT than interventricular dyssynchrony.

Dyssynchrony is assessed by surface ECG. Most of the landmark trails have used surface ECG to define Dyssynchrony. And best tool to assess mechanical Dyssynchrony is echocardiography.

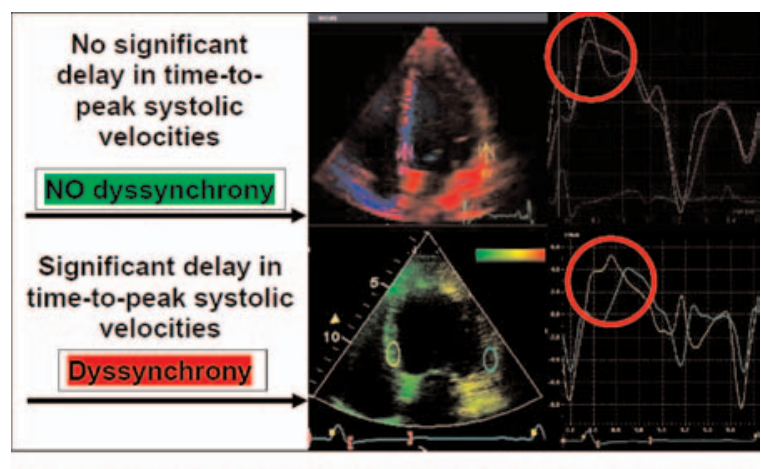

Top panel: color coded image and TDI waveforms display no significant delay in time-to-peak systolic TDI velocities between the septal and lateral walls (circle) no dyssynchrony. Bottom panel: color code image and the TDI waveforms indicating significant delay in timing of contraction between the septal and lateral walls (circle), consistent with significant dyssynchrony.

Figure 1: Normal versus dyssynchrony of myocardial contraction; 'Take out your workbook CRT' by ASE; June 2007.

Definition of Cardiac resynchronization therapy (CRT) CRT or Biventricular pacemaker is a treatment for selected patients with heart failure-induced conduction disturbances 
and ventricular dyssynchrony. CRT with a programmed short PR interval helps to reduce symptoms and improve cardiac function by restoring the mechanical sequence of ventricular activation and contraction when used in combination with stable, optimal medical therapy. There are three leads system in CRT device for right atrium, right ventricle and left ventricle. LV lead is placed in the epicardial surface of Left ventricular wall via the coronary sinus. The right ventricular lead activates interventricular septum. The left lateral ventricular wall is activated by the coronary sinus lead. Thus the cardiac resynchronization is gained by simultaneous activation of LV and RV by using CRT.

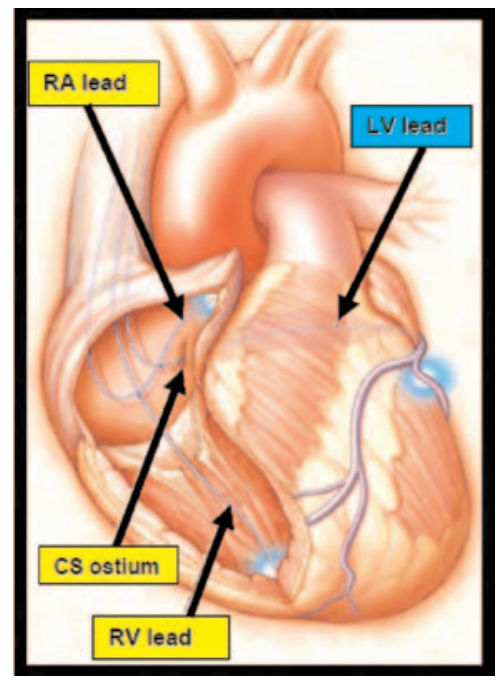

Figure 2: Cardiac resynchronization therapy with three leads system; 'Take out your workbook CRT' by ASE; June 2007.

\section{Evidence for CRT}

The preliminary results of the Multisite Stimulation in Cardiomyopathies (MUSTIC) ${ }^{3}$, Multicenter InSync Randomized Clinical Evaluation (MIRACLE), Pacing Therapy for Congestive Heart Failure (PATH-CHF), InSync, Contak CD, CARE-HF and VIGOR CHF22 studies have been published. End points of these trials may be divided into early and intermediate, as there are no long term-randomised data. And these end points are assessed by functional, symptomatic, mortality, physiological and health economic aspect.

Functional end points assessed include 6-minute walk tests, Peak $\mathrm{VO}_{2}$, treadmill testing and NYHA class.

Symptomatic factors also influence NYHA class but were often more precisely assessed by the Minnesota living with heart failure questionnaire (MLHFQ), which is a 21-stem assessment in which responders are asked to rate the effect of their heart failure symptoms on their quality of life. Mortality data assessed as total cardiovascular or heart failure-related mortality.
Physiological end points used may be structural (echocardiographic measurements are commonly used) and arrhythmic (development of atrial fibrillation or ventricular arrhythmias). Other measurements are blood haemoglobin and renal function tests. Health economic data were obtained from number of hospitalization.

InSync and MUSTIC ${ }^{3}$ were uncontrolled, whereas the CARE-HF, MIRACLE, PATH-CHF, Contak CD and VigorCHF studies were randomized or double-blind (MIRACLE) and controlled trials. All seven of these studies provide promising results.

The CARE-HF study is the first study to show benefit with CRT with respect to survival, and the first to show benefit and continued improvement for a period of over two years. It is a reliable study which included 813 patients of heart failure with NYHA class III or IV due to LV dysfunction and cardiac dyssynchrony who were receiving standard OPT. The patients were randomly assigned to receive medical therapy alone or with CRT. A 37\% reduction in combined all cause mortality or unplanned cardiovascular hospitalizations and improved heart failure symptoms and quality of life (Primary end-point) and 36\% reduction in all cause mortality (secondary end-point)

Table 1: The CARE-HF study outcomes ${ }^{4}$.

\begin{tabular}{|c|c|c|c|c|}
\hline Out comes & $\begin{array}{l}\text { Medical } \\
\text { therapy } \\
\text { alone }(n=404)\end{array}$ & $\begin{array}{l}\text { Medical } \\
\text { therapy plus } \\
\text { CRT }(n=409)\end{array}$ & \begin{tabular}{|l|} 
Hazard \\
ratio $(95 \%$ \\
CI $)$
\end{tabular} & P value \\
\hline \begin{tabular}{|l|} 
1.Primary \\
outcome: \\
a)Death or \\
unplanned \\
hospitalization for \\
cardiovascular event
\end{tabular} & $224(55)$ & $159(39)$ & $\begin{array}{l}0.63(0.51 \text { to } \\
0.77)\end{array}$ & $<0.001$ \\
\hline $\begin{array}{l}\text { b) Unplanned } \\
\text { hospitalization for } \\
\text { cardiovascular event }\end{array}$ & $184(46)$ & $125(31)$ & $\begin{array}{l}0.61(0.49 \text { to } \\
0.77)\end{array}$ & $<0.001$ \\
\hline $\begin{array}{l}\text { 2. Secondary } \\
\text { outcome: } \\
\text { a) Death from any } \\
\text { cause }\end{array}$ & $120(30)$ & $82(20)$ & $\begin{array}{l}0.64(0.48 \text { to } \\
0.85)\end{array}$ & $<0.002$ \\
\hline $\begin{array}{l}\text { b) Death from any } \\
\text { cause or Unplanned } \\
\text { hospitalization with } \\
\text { worsening of heart } \\
\text { failure }\end{array}$ & $191(47)$ & $118(29)$ & $\begin{array}{l}0.54(0.43 \text { to } \\
0.68)\end{array}$ & $<0.001$ \\
\hline $\begin{array}{l}\text { c) Unplanned } \\
\text { hospitalization with } \\
\text { worsening of heart } \\
\text { failure. }\end{array}$ & $133(33)$ & $72(18)$ & $\begin{array}{l}0.48(0.36 \text { to } \\
0.64)\end{array}$ & $<0.001$ \\
\hline $\begin{array}{l}\text { (90 days out come) } \\
\text { 3. Continuous } \\
\text { outcome: }\end{array}$ & $\begin{array}{l}\text { Medical } \\
\text { therapy alone } \\
(\mathrm{N}=404)\end{array}$ & $\begin{array}{l}\text { Medical } \\
\text { therapy plus } \\
\text { CRT }(\mathrm{N}=409)\end{array}$ & $\begin{array}{l}\text { Difference } \\
\text { in means }(95 \\
\% \mathrm{CI})\end{array}$ & P value \\
\hline a) NYHA class & $2.7 \pm 0.9$ & $2.1 \pm 1.0$ & $\begin{array}{l}0.6(0.4 \text { to } \\
0.7)\end{array}$ & $<0.001$ \\
\hline $\begin{array}{l}\text { b) Minnesota living } \\
\text { with heart failure } \\
\text { score }\end{array}$ & $40 \pm 22$ & $31 \pm 22$ & $-10(-8$ to -12$)$ & $<0.001$ \\
\hline $\begin{array}{l}\text { c) EuroQoL EQ-5D } \\
\text { score }\end{array}$ & $0.63 \pm 0.29$ & $0.70 \pm 0.28$ & $\begin{array}{l}0.08(0.04 \text { to } \\
0.12)\end{array}$ & $<0.001$ \\
\hline
\end{tabular}


Table 2: Effect of Cardiac Resynchronization on Health status Measures in AHA science Advisory. ${ }^{5}$ Ongoing studies include the PATH II study, CARE-HF 4, BELIEVE, VecToR, PACMAN, Contak CD (continued access protocol, recently completed enrollment) and one large randomized, controlled study entitled the comparison of medical therapy, Pacing, and Defibrillation in Chronic Heart Failure (COMPANION) trial ${ }^{6}$.

The following table summarized the results of other trials:

\begin{tabular}{|c|c|c|c|c|c|c|c|c|c|c|c|c|}
\hline & \multicolumn{2}{|c|}{$\begin{array}{l}\text { MUSTIC-SR }{ }^{1} \\
(\mathrm{n}=58, \mathrm{~F} / \mathrm{U} 12 \mathrm{wk})\end{array}$} & \multicolumn{2}{|c|}{$\begin{array}{l}\text { PATH-CHF } \\
(\mathrm{n}=40, \mathrm{~F} / \mathrm{U} 4 \mathrm{wk})\end{array}$} & \multicolumn{2}{|c|}{$\begin{array}{c}\text { MIRACLE }^{3} \\
(\mathrm{n}=453, \mathrm{~F} / \mathrm{U} 6 \mathrm{mo})\end{array}$} & \multicolumn{2}{|c|}{$\begin{array}{l}\text { MIRACLE-ICD } \\
(\mathrm{n}=369, \mathrm{~F} / \mathrm{U} 6 \mathrm{mo})\end{array}$} & \multicolumn{2}{|c|}{$\begin{array}{l}\text { CONTAK CD } \\
(\mathrm{n}=490, \mathrm{~F} / \mathrm{U} 3-6 \mathrm{mo})\end{array}$} & \multicolumn{2}{|c|}{$\begin{array}{l}\text { COMPANION }^{6} \\
(\mathrm{n}=1520, \mathrm{~F} / \mathrm{U} 6 \mathrm{mo})\end{array}$} \\
\hline & Introl & $\mathrm{CRT}^{*}$ & Control & $\mathrm{CRT}^{*}$ & Control & $\mathrm{CRT}^{*}$ & Control & CRT $^{*}$ & Control & $\mathrm{CRT}^{*}$ & Control & CRT $^{*}$ \\
\hline \multirow{4}{*}{$\begin{array}{l}\text { 6-Min walk test, M } \\
\text { Peak oxygen uptake } \\
\text { mL. min }{ }^{-1} \cdot \mathrm{Kg}^{-1} \\
\text { NYHA, \% I/II/III/IV } \\
\text { Minnesota Living With } \\
\text { Heart Failure } \\
\text { Questionnaire }\end{array}$} & \multirow{3}{*}{\multicolumn{2}{|c|}{$\begin{array}{lr}\ldots & 74 \\
\ldots & 1.2 \\
\text { Before } & \ldots \\
0 / 0 / 100 / 0 & \end{array}$}} & \multirow{3}{*}{\multicolumn{2}{|c|}{$\begin{array}{lc}\ldots & 74 \\
\ldots & 1.2 \\
\text { Before } \quad \text { After } \\
0 / 0 / 85 / 15 & 15 / 34 / 44 / 7\end{array}$}} & \multirow{3}{*}{\multicolumn{2}{|c|}{$\begin{array}{ll}10 & 39 \dagger \\
0.2 & 1.1 \dagger \\
38 \% \text { of } & 68 \% \text { of } \\
\text { patients? } & \text { patients? }\end{array}$}} & \multirow{3}{*}{\multicolumn{2}{|c|}{$\begin{array}{ll}55 & 53 \\
0.1 & 11 \dagger \\
\text { Mean } & \text { Mean:- } 1 \\
? & \text { NYHA class } \dagger\end{array}$}} & \multirow{3}{*}{\multicolumn{2}{|c|}{ 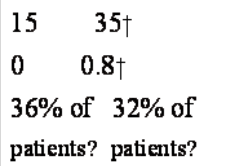 }} & \multirow{3}{*}{\multicolumn{2}{|c|}{$\begin{array}{ll}1 & 40 \dagger \\
\ldots & \ldots \\
38 \% \text { of } & 61 \% \text { of } \\
\text { patients? } & \text { patients? }\end{array}$}} \\
\hline & & & & & & & & & & & & \\
\hline & & & & & & & & & & & & \\
\hline & & -14 & ... & & -9 & & $\begin{array}{ll}-11 & -17\end{array}$ & & $+5 \quad-7 \dagger$ & & -12 & \\
\hline
\end{tabular}

MUSTIC-SR indicates Multisite Stimulation in Cardiomyopathies, PATH- CHF, Pacing Therapies in Congestive Heart Failure; MIRACLE, Multicenter InSync Randomized Clinical Evaluation, MIRACLE-ICD, MIRACLE-implantable cardioverter defibrillator, CONTAK CD, combined heart failure/ bradycardia/ tachycardia ICD device, companion, Comparison of Medical Therapy, Pacing, and Defibrillation in Heart Failure ? indicates decreased; ? no change mean, mean change in NYHA class; and F/U follow- up,

* Comparison is with baseline.

$\dagger \mathrm{p}<0.05$ for comparison with control

$\ddagger$ Lower score indicates improved quality of life

\section{Selection of patients for CRT implantation}

- Chronic heart failure patients on OPT (ACEI/ARB + $\mathrm{BB}+$ Spironolactone + Diuretic),

- Symptomatic patients in NYHA class III or IV,

- LVEF is $35 \%$ or less

- QRS duration $>150 \mathrm{~ms}$ or $>120 \mathrm{~ms}+$ mechanical dyssynchrony,

- Sinus rhythm

The ESC has published a new guideline for the selection of patients?

- Chronic heart failure patients on OPT,

- NYHA class III and IV,

- LVEF is $35 \%$ or less,

- QRS duration $>120 \mathrm{~ms}$,

- Sinus rhythm.

But a trial has been shown no benefit from CRT in moderate to severe heart failure with narrow QRS interval. There was no improvement peak oxygen consumption after CRT implantation in this randomised trial ${ }^{8}$.

\section{Assessment of patients before CRT device implantation}

\section{Assessment of patient's symptoms}

a) Patient must be in stable state of optimum medical treatment,

b) Dyspnoea scored in NYHA class III and IV,

\section{Assessment Investigations}

a) Dyssynchrony echocardiography

Cardiac Dyssynchrony can be evident by detecting-
Abnormal septal motion, reduced left ventricular filling time, decreased ejection fraction, increased end systolic volume, mitral regurgitation which start even before systole (presystolic), aortic valve opening and closing both are delayed etc.

Markers of Dyssynchrony:

1. LV-PEP $>140 \mathrm{~ms}$

2. D-PEP $>40 \mathrm{~ms}$

3. T-IVT $>15 \mathrm{~s} / \mathrm{min}$

4. Difference in TDI between any site $>65 \mathrm{~ms}$ (best if delay is posterior-lateral)

Echocardiographic measurements are being used to assess cardiac Dyssynchrony. According to 'PROSPECT Trial' The echocardiographic parameters assessing Dyssynchrony do not have enough predictive value to be recommended as selection criteria for cardiac resynchronization therapy beyond current indications. Most of the large trials have used the echocardiographic study to assess left ventricular $\mathrm{EF}^{9}$.

b) Cardiac MRI (CMR)

If there is facility for cardiac MRI then it is better to do it before CRT implantation as CMR can detect the area of fibrosis and dyssynchrony.

c) Nuclear scintigraphy

It may be done to see the viability of lateral wall of $\mathrm{LV}$ before CRT implantation. 


\section{CRT-P versus CRT-D}

CRT-D gives additional anti arrhythmic effect in heart failure patient with poor left ventricular function. ${ }^{10}$

In large randomised trial COMPANION has showed more mortality benefit with CRT-D than CRT-P or optimum pharmacological therapy (OPT) alone.

\section{Cost effectiveness}

CARE-HF and COMPANION both the trials have done cost effective analysis of CRT-P and CRT-D in contrast to traditional pharmacological therapy. In COMPANION study, investigator estimate incremental cost effectiveness ratios (ICER) in comparison of optimal pharmacological therapy (OPT), CRT-P and CRT-D. The hospitalization costs after 2 years of implantation were reduced by $29 \%$ for CRT-D and $37 \%$ for CRT-P. Another follow up analysis after 7 years time, ICER for CRT-P was 19,600 dollars per quality adjusted life years (QALYs) and the ICER for CRT-D was 43,000 dollars per QALY relation to OPT. This result suggests that the clinical benefits of CRT-P and CRT-D can be achieved at a reasonable cost ${ }^{11}$.

In CARE-HF trial has shown that CRT reduced to morbidity and mortality but the cost effectiveness of this therapy remains uncertain. They studied about the incremental cost per QALY gained and incremental cost per life year gained of CRT plus medical therapy compared to medical therapy alone. Treatment with CRT appears cost-effective. It costs 29,400 Euros (20,000 pounds sterling) per QALY ${ }^{12}$.

In a recent analysis of cost effectiveness in Scandinavian region i.e. Denmark, Finland, Sweden was done based on CARE-HF trials which indicates that CRT is cost effective treatment in their health care system than traditional pharmacological therapy. Investigators recommended CRT for heart failure patients NYHA class III and IV and evidence of dyssynchrony ${ }^{13}$.

\section{Assessment of CRT response}

After implantation of Cardiac resynchronization therapy in a heart failure patient stroke volume increases as well as cardiac output and end systolic volume decreases. Pulmonary capillary wedge pressure is also decreased ${ }^{14,15}$.

Several randomized clinical trials demonstrate that CRT Improves functional measurements of heart failure severity, decreases NYHA score, improved quality of life scoresQoL (measured by Quality of life questionnaires) and exercise tolerance.

Decreased left ventricular size and improvement of LV ejection fraction.

Decreases heart failure re-hospitalizations.

Decreases heart failure mortality.

\section{Unresolved issues for CRT}

1) Atrial fibrillation (AF):

A recent prospective observational study of 295 consecutive patients with heart failure (permanent AF in 66; paroxysmal AF in 20; sinus rhythm in 209) underwent CRT implantation. They have followed up for 6.8 years. There are no differences in prognosis, hospitalisation rates, symptoms, or improvement in LV remodelling ${ }^{16}$.

2) NYHA class I or II:

The MADIT-CRT trial is designed to determine if CRT-D will reduce the risk of mortality and heart failure events by approximately $25 \%$ in patients with ischaemic (NYHA class I-II) and non-ischaemic (NYHA class II) cardiomyopathy, left ventricular dysfunction ( $\mathrm{EF}<$ or $30 \%$ ), and prolonged intra ventricular conduction (QRS duration $>$ or $130 \mathrm{~ms})^{17}$.

3) Right bundle branch block (RBBB):

In heart failure patient, mechanical dyssynchrony is less common in RBBB than LBBB. The right ventricular pacing has shown the same efficacy as CRT in pure RBBB conduction delay ${ }^{18}$.

\section{Conclusions}

Cardiac resynchronization therapy may be the answer for selected heart failure patients. Although CRT devices are expensive, the costs may be offset in part by savings from reduced hospitalization for heart failure. But large randomized trials showed about $30 \%$ of nonresponder. Multidisciplinary approaches are needed for the management of these patients. That is why investigators are concentrating on careful preimplant assessment i.e. prediction of responders to cardiac resynchronization therapy. In the future, CRT may be used in a wider range of patients with heart failure.

\section{References}

1. Baldasseroni, S., Opasich, C., Gorini, M., Lucci, D., Marchionni, N., Marini, M., Campana, C., Perini, G., Deorsola, A., Masotti, G., Tavazzi, L., \& Maggioni, A. P. Left bundle-branch block is associated with increased 1-year sudden and total mortality rate in 5517 outpatients with congestive heart failure: a report from the Italian network on congestive heart failure, Am. Heart J, 2002; 143 (3): 398-405.

2. Cowie, M. R., Fox, K. F., Wood, D. A., Metcalfe, C., Thompson, S. G., Coats, A. J., Poole-Wilson, P. A., \& Sutton, G. C. Hospitalization of patients with heart failure: a population-based study, Eur Heart J, 2002; 23: 877-85.

3. Linde, C., Leclercq, C., Rex, S., Garrigue, S., Lavergne, T., Cazeau, S., McKenna, W., Fitzgerald, M., Deharo, J. C., Alonso, C., Walker, S., Braunschweig, F., Bailleul, C., \& Daubert, J. C. Long-term benefits of biventricular pacing in congestive heart failure: results from the MUltisite STimulation in cardiomyopathy (MUSTIC) study, J.Am.Coll.Cardiol, 2002; 40(1): 111-18. 
4. Cleland, J. G., Daubert, J. C., Erdmann, E., Freemantle, N., Gras, D., Kappenberger, L., \& Tavazzi, L. The effect of cardiac resynchronization on morbidity and mortality in heart failure, New England Journal of Medicine, 2005; 352: 1539-49.

5. Strickberger, S. A., Conti, J., Daoud, E. G., Havranek, E., Mehra, M. R., Pina, I. L., \& Young, J. Patient selection for cardiac resynchronization therapy: from the Council on Clinical Cardiology Subcommittee on Electrocardiography and Arrhythmias and the Quality of Care and Outcomes Research Interdisciplinary Working Group, in collaboration with the Heart Rhythm Society, Circulation, 2005; 111(16): 2146-50.

6. Carson, P., Anand, I., O'Connor, C., Jaski, B., Steinberg, J., Lwin, A., Lindenfeld, J., Ghali, J., Barnet, J. H., Feldman, A. M., \& Bristow, M. R. Mode of death in advanced heart failure: the Comparison of Medical, Pacing, and Defibrillation Therapies in Heart Failure (COMPANION) trial, J.Am.Coll.Cardiol, 2005; 46(12): 2329-34.

7. Vardas et.al. New guide lines for selection of patients for Cardiac resynchronization therapy implantation, ESC guideline for heart failure, 2007;

8. Beshai, J. F., Grimm, R. A., Nagueh, S. F., Baker, J. H., Beau, S. L., Greenberg, S. M., Pires, L. A., \& Tchou, P. J. Cardiacresynchronization therapy in heart failure with narrow QRS complexes, N.Engl.J.Med, 2007; 357(24): 2461-71.

9. Chung, E. S., Leon, A. R., Tavazzi, L., Sun, J. P., Nihoyannopoulos, P., Merlino, J., Abraham, W. T., Ghio, S., Leclercq, C., Bax, J. J., Yu, C. M., Gorcsan, J., III, St John, S. M., De, S. J., \& Murillo, J. Results of the Predictors of Response to CRT (PROSPECT) trial, Circulation, 2008; 117(20): 2608-16.

10. Ermis, C. \& Benditt, D. G. Cardiac resynchronization pacing without defibrillator capability: is this a viable option? Europace, 2006; 8(7): 499-501.

11. Feldman, A. M., de, L. G., Bristow, M. R., Saxon, L. A., De, M. T., Kass, D. A., Boehmer, J., Singh, S., Whellan, D. J., Carson, P., Boscoe, A., Baker, T. M., \& Gunderman, M. R. Cost effectiveness of cardiac resynchronization therapy in the Comparison of Medical Therapy, Pacing, and
Defibrillation in Heart Failure (COMPANION) trial, J.Am.Coll.Cardiol, 2005; 46(12): 2311-21.

12. Calvert, M. J., Freemantle, N., Yao, G., Cleland, J. G., Billingham, L., Daubert, J. C., \& Bryan, S. Cost-effectiveness of cardiac resynchronization therapy: results from the CARE-HF trial, Eur.Heart J, 2005; 26(24): 2681-88.

13. Blomstrom, P., Ekman, M., Blomstrom, L. C., Calvert, M. J., Freemantle, N., Lonnerholm, S., Wikstrom, G., \& Jonsson, B. Cost effectiveness of cardiac resynchronization therapy in the Nordic region: An analysis based on the CARE-HF trial, Eur.J.Heart Fail, 2008;

14. Kass, D. A., Chen, C. H., Curry, C., Talbot, M., Berger, R., Fetics, B., \& Nevo, E. Improved left ventricular mechanics from acute VDD pacing in patients with dilated cardiomyopathy and ventricular conduction delay, Circulation, 1999; 99(12): 1567-73.

15. Leclercq, C., Cazeau, S., Le, B. H., Ritter, P., Mabo, P., Gras, D., Pavin, D., Lazarus, A., \& Daubert, J. C. Acute hemodynamic effects of biventricular DDD pacing in patients with end-stage heart failure, J.Am.Coll.Cardiol, 1998; 32(7):1825-31.

16. Khadjooi, K., Foley, P. W., Chalil, S., Anthony, J., Smith, R. E., Frenneaux, M. P., \& Leyva, F. Long-term effects of cardiac resynchronisation therapy in patients with atrial fibrillation, Heart, 2008; 94(7):879-83.

17. Moss, A. J., Brown, M. W., Cannom, D. S., Daubert, J. P., Estes, M., Foster, E., Greenberg, H. M., Hall, W. J., Higgins, S. L., Klein, H., Pfeffer, M., Wilber, D., \& Zareba, W. Multicenter automatic defibrillator implantation trial-cardiac resynchronization therapy (MADIT-CRT): design and clinical protocol, Ann.Noninvasive.Electrocardiol, 2005; 10(4) Suppl:34-43.

18. Byrne, M. J., Helm, R. H., Daya, S., Osman, N. F., Halperin, H. R., Berger, R. D., Kass, D. A., \& Lardo, A. C. Diminished left ventricular dyssynchrony and impact of resynchronization in failing hearts with right versus left bundle branch block, J.Am.Coll.Cardiol, 2007; 50(15):1484-90 